\title{
On fatigue life prediction of Al-alloy 2024 plates in riveted joints
}

\author{
Reza Masoudi Nejad ${ }^{\mathrm{a}, *}$, Filippo Berto ${ }^{\mathrm{b}}$, Greg Wheatley ${ }^{\mathrm{c}}$, Mohammadreza Tohidi ${ }^{\mathrm{d}}$, \\ Wenchen $\mathrm{Ma}^{\mathrm{e}}$ \\ a School of Mechanical and Electrical Engineering, University of Electronic Science and Technology of China, Chengdu 611731, China \\ ${ }^{\mathrm{b}}$ Department of Mechanical and Industrial Engineering, NTNU - Norwegian University of Science and Technology, Trondheim, Norway \\ ${ }^{\mathrm{c}}$ College of Science and Engineering, James Cook University, Townsville QLD Australia \\ ${ }^{\mathrm{d}}$ Department of Mechanical Engineering, Foolad Institute of Technology, Fooladshahr, Isfahan, Iran \\ ${ }^{\mathrm{e}}$ Department of Civil and Environmental Engineering and Construction, University of Nevada, Las Vegas, 4505 S. Maryland Parkway, Las Vegas, NV 89154, USA
}

\section{A R T I C L E I N F O}

\section{Keywords:}

Equivalent plastic strain

Fatigue crack growth

Boundary element methods

Riveted joint

Al-alloy 2024 plate

\begin{abstract}
A B S T R A C T
The purpose of this paper is to numerically investigate the fatigue life and the fatigue crack growth path of 2024 aluminum plate riveted joints. For this purpose, according to field observations, the parameters affecting fatigue life are obtained. Relevant geometric parameters such as rivet shank length, hole diameter and dimensional tolerances, as well as the location pattern of the rivets and the material of the rivet joints are studied. In this study, modeling is performed to calculate the equivalent plastic strain using the finite element method. For this purpose, a three-dimensional elastoplastic model is used for simulation. The information obtained from the finite element method in this study made it possible to place the rivets in this type of joint for use in high safety structures such as the aerospace industry. Given the importance of the problem of crack growth in 2024 aluminum plates, having the geometrical and physical parameters of the problem, the goal is to achieve the exact path of crack growth and fatigue life of riveted joints. Fatigue crack growth simulation is performed on the samples using the boundary element method. The stress intensity factor for different loading modes is determined using the boundary element method. The results showed that the geometric parameters and the rivet material have a significant effect on fatigue cracking in aluminum plates.
\end{abstract}

\section{Introduction}

The riveting process is one of the most important types of connections in various industries, especially the aerospace industry. The fatigue of the rivet joint in the plates of the aircraft fuselage structure is directly related to the residual stress state in the joint. In addition to the importance of predicting the fatigue life of rivet joints, it should also be possible to evaluate the moment of the fatigue failure process during loading so that appropriate measures can be taken to prevent structural failure if necessary [1-3]. In recent decades, many studies have been performed on the static behavior and fatigue of automatic riveting joints. Krause and Cherenkoff performed fatigue test points to compare the performance of automatic rivet joints and weld joints [4]. Ferro and Petrone [5] investigated the development of thermal and residual stress distributions arising from the solidification of a fusion zone near a Vnotch tip. Ferro [6] studied the residual stress distribution induced by the solidification and cooling of a fusion zone in the vicinity of a sharp V- notch tip is investigated. Borsato et al. [7] examined mechanical and fatigue properties of heavy section solution strengthened ferritic ductile irons castings. The material showed high homogeneity in the whole casting, considering tensile and hardness tests. Hahn et al. made a comparison between the performance of an automatic rivet joint and the case where it was combined with an adhesive joint. They concluded that the combined use of rivet and adhesive joints results in increased static strength and fatigue [8]. Fu and Mallick investigated the effect of rivet and mold dimensions on the static properties and fatigue of automatic rivet joints [9]. Fu and Malik then studied the fatigue behavior of automatic rivet joints in 6111-T4 aluminum plates [10]. Fatigue behavior of single and double automatic rivet joints that connect 5754-O aluminum plates was performed by Iyer et al. [11]. Iyer et al. used three specimens with three different thicknesses to connect single rivets. Different arrangements for rivet placement were used to examine the connections of the double rivet. Ekvall presented a simple finite element model for stress analysis in rivet joints and obtaining local stress and

\footnotetext{
* Corresponding author.

E-mail addresses: masoudinejad@uestc.edu.cn (R. Masoudi Nejad), filippo.berto@ntnu.no (F. Berto), greg.wheatley@jcu.edu.au (G. Wheatley), r_tohidi@yahoo. com (M. Tohidi), maw2@unlv.nevada.edu (W. Ma).
} 
strain and critical locations for fatigue load [12]. Fung and Smart analyzed the static strength and fatigue of the two types of universal rivet and countersunk joints using the finite element method [13]. Szolwinski showed in an experimental study that the fatigue life of a rivet joint is highly dependent on the riveting force [14]. The result showed that the amount of residual stress created in the joint due to the riveting process is directly related to the size of the hammer riveting force. Among the numerous numerical methods available to solve problems, three of them can be named as the most well-known methods. With respect to emersion, these are the element free method (EFM), the boundary element method (BEM) [15-20] and the finite element method (FEM) [21-27], respectively. Abundant researches are performed in the field of evaluating the parameters affecting fatigue crack growth [28-32]. Trego investigated the effect of compressive residual stresses on rivet joints on static strength and fatigue [33]. In addition, Targo observed that increasing the level of residual stress due to the riveting process increases the fatigue life. By applying a hammer blow, the rivet increases in volume and fills the hole. After the riveting process, the wall of the hole puts compressive stress on the rivet. Blanchot simulated the riveting process using several finite element methods with the aim of finding the right size for the model and reducing the computation time [34]. Rijck obtained a theoretical relationship between the riveting force and the rivet tail diameter [35]. He then investigated the validity of his relationships using experiments. The relationships between elastic deformation, plasticity and loading stage in the riveting process were obtained by Kaifu et al. [36]. Calculation of stress intensity factor is required in order to achieve fatigue life by ParisErdogan method. Applying multi-location damage theory is one way to calculate the stress intensity factor in the aircraft fuselage structure. Beuth and Hutchinson investigated a cracked edge rivet joint [37]. Wang et al. examined the stress intensity factor and fatigue life in a cracked three-row rivet joint using the theory of multi-location damage [38]. The fatigue life of cracked countertop rivet joints was obtained experimentally by creating grooved specimens at the crack edge by Park et al. [39]. Moreira et al. investigated the stress intensity factor in a rivet joint with one or two cracks and considered the effect of load transfer [40].

In most studies on the fatigue life of rivet joints in aluminum plates, fatigue relationships have been used to evaluate the life of riveted joints. Since many parameters affect the mechanical properties of the joint, in this paper, first, the equivalent plastic strain distribution was determined using a three-dimensional elastoplastic finite element model. Then, using the boundary element method, crack growth in 2024 aluminum plates has been investigated.

\section{Riveted joint structures}

A simple riveting process does not require pre-prepared surfaces. Also, different materials can be connected with a simple rivet. Opening the connection can only be done by destroying the rivet. To perform the riveting process, all parts must be homogeneous, pre-drilled and fixed by a suitable retainer. Thin plate joints include tubes, plates, and thin pieces that are stacked on top of each other. The riveting process is only used for edge joints. Fig. 1 shows the types of riveted joints.

Today, riveted joints have found many applications due to its increasing use, especially in the aerospace industry. In structural applications, due to the service life, fatigue is considered as the most important form of loading. One of the most important issues in the construction of structures with a rivet connection is its ability to connect and assemble. Design and construction of joints with suitable strength in these structures is very necessary. Most research has been done with the concepts of failure mechanics to predict the fatigue life of riveted joints. Therefore, in this paper, the fatigue behavior of aluminum alloy plate in riveted joint is investigated.

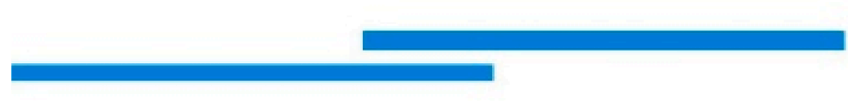

(a)
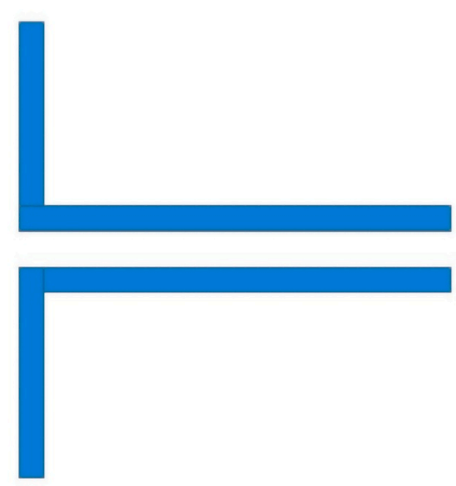

(b)

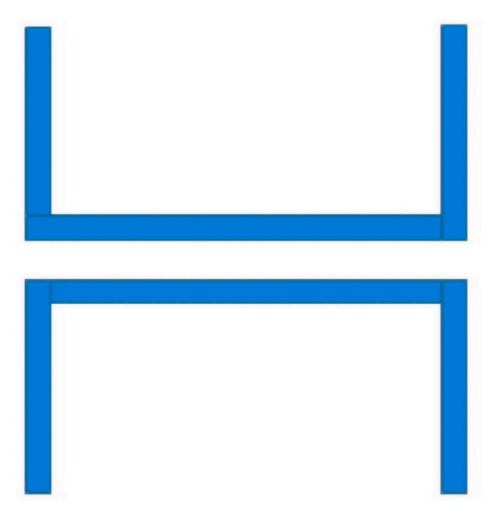

(C)

Fig. 1. Types of riveted joints: (a) lap joint, (b) T joint, (c) U joint.

\section{Finite element method}

Due to the characteristics and extent of 2024 aluminum in the aerospace industry, in this paper, the parameters affecting the fatigue life of this alloy are investigated. Due to the fact that the study is to investigate the fatigue crack growth of riveted joints in 2024 aluminum alloy plates, plate and rivets are made of this material. The chemical composition of 2024 aluminum, which is the sample used in the present study, is presented in Table 1 . Also the mechanical properties of the materials are presented in Table 2 . To create the specimens, aluminum plates with dimensions of $75 * 140 \mathrm{~mm}$ and a thickness of $1.70 \mathrm{~mm}$ were modeled. The diameter of the rivet shank length is $2.8 \mathrm{~mm}$. Also, other effective parameters on riveted joints are presented in Table 3.

To calculate the deformation in different stages of the riveting process, the riveted joint was evaluated using the finite element method. Fig. 2 shows an example of a finite element model for riveted joints in 2024 aluminum plates. Due to the presence of fillets in the corners of the holes of the sheets, the mesh is irregular. The geometry was partitioned to arrange the meshes. For areas with concentrated stress, the local grain size is $0.6 \mathrm{~mm}$ and for the general grain size of the set is $5 \mathrm{~mm}$. Moreover, the higher the friction coefficient is, the shorter the component life will be $[1,41]$. Therefore, friction coefficient values are selected for the lubricated state. General-contact is defined for the whole assembly and self-contact is defined for rivets. All the degrees of freedom of the punch are fixed and at this step the "surface to surface" contact is used for all surfaces, instead of general contact. The symmetry boundary condition is applied for the whole assembly since it is halved from the middle due to its symmetry. Beneath all the rivets head is completely fixed. The 
Table 1

Chemical analysis of 2024 Aluminum (in wt \%) [1].

\begin{tabular}{|c|c|c|c|c|c|c|c|c|c|}
\hline Aluminum & $\mathrm{Al}$ & $\mathrm{Cr}$ & $\mathrm{Cu}$ & $\mathrm{Fe}$ & $\mathrm{Mg}$ & Mn & $\mathrm{Si}$ & $\mathrm{Ti}$ & $\mathrm{Zn}$ \\
\hline 2024 Aluminum & $94-90.7$ & 0.1 & $4.9-3.8$ & 0.5 & $1.2-1.8$ & $0.9-0.3$ & 0.05 & 0.15 & 0.25 \\
\hline
\end{tabular}

Table 2

Mechanical properties of materials used in experiments [1].

\begin{tabular}{llllll}
\hline $\begin{array}{l}\text { Related } \\
\text { model }\end{array}$ & material & $\begin{array}{l}\text { Young } \\
\text { modulus } \\
{[\mathrm{MPa}]}\end{array}$ & $\begin{array}{l}\text { Poisson } \\
\text { ratio }\end{array}$ & $\begin{array}{l}\text { Yield } \\
\text { strength } \\
{[\mathrm{MPa}]}\end{array}$ & $\begin{array}{l}\text { Ultimate } \\
\text { tensile } \\
\text { strength } \\
{[\mathrm{MPa}]}\end{array}$ \\
\hline rivet & $\begin{array}{l}\text { Al2024- } \\
\text { T4 }\end{array}$ & 69824.3 & 0.33 & 244.38 & 402.63 \\
plate & $\begin{array}{l}\text { Al2024- } \\
\text { T3 }\end{array}$ & 71572.0 & 0.33 & 378.02 & 571.92 \\
\hline
\end{tabular}

Table 3

The effective parameter on equivalent plastic strain of riveted joints.

\begin{tabular}{llll}
\hline parameters & Level 1 & Level 2 & Level 3 \\
\hline Rivet shank length & 7 & 8 & 9 \\
Punch pressure (MPa) & 1.4 Sy & 1.6 Sy & 1.8 Sy \\
the number of lateral holes & 2 & 4 & 3 \\
the number of longitudinal holes & 3 & 1 & 3 \\
\hline
\end{tabular}

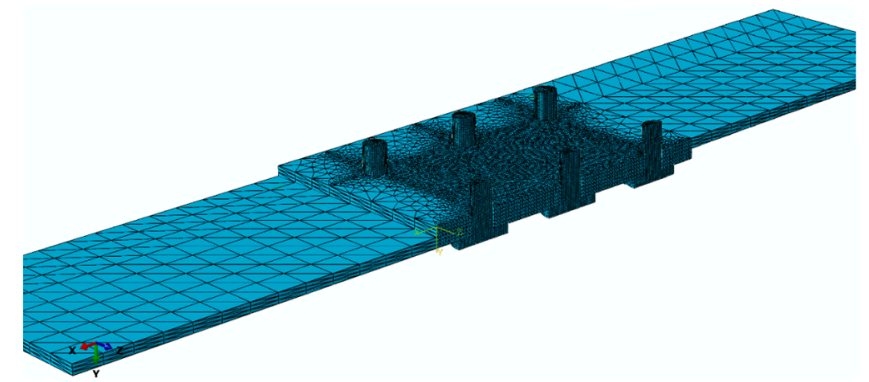

Fig. 2. Finite element model of the studied sample.

simulation of riveting is carried out in two steps in order to improve significantly the calculation cost. First, the rivets are inserted into the holes and then punched. Second, the friction force between the punch and the rivet is removed and only the normal force between the punch and the rivet remains. The punch is kept under constant pressure until the model is ready to be applied tensile force. Following the punching simulation step, the following steps should be performed to simulate the traction process. One side of the plates is loaded $23 \mathrm{kN}$ and the other side is bound.

The equivalent plastic strain results for the 3 levels presented in Table 3 are shown in Figs. 3-5. Now, since the cost function of the maximum plastic strain is equivalent to the plates, it should be noted that the integral point parameter including strain is read from the integral points; otherwise, by reading from nodes, they will be read more than their real value. Table 4 shows the maximum equivalent plastic strain values on the plates in these three levels. As can be seen for the level 3 , the equivalent plastic strain value is less than all other levels and can be considered as the best condition for the effective parameters (Fig. 6).

\section{Fatigue crack growth and life estimation}

The plastic zone is formed at the crack tip under constant amplitude cyclic loading. This plastic zone prevents the growth of cracks. If the plastic zone is small enough that the elastic zone surrounds it, the condition of the crack tip is expressed in terms of the stress intensity factor. The crack growth relationship is obtained as a function of Eq. (1) [42-45]:

$\frac{d a}{d N}=f_{I}(\Delta K, R)$

where $\mathrm{R}$ is the stress ratio and $\Delta K$ is the stress intensity factor range. Therefore, the number of cycles performed for the growth of a crack from the initial length $\left(a_{0}\right)$ to the final length $\left(a_{f}\right)$ is obtained from Eq. (2):

$N=\int_{a_{0}}^{a_{f}} \frac{d a}{f_{I}(\Delta K, R)}$

If $R=0$ then Eq. (2) is as follows:

$N=\int_{a_{0}}^{a_{f}} \frac{d a}{C(\Delta K)^{m}}$

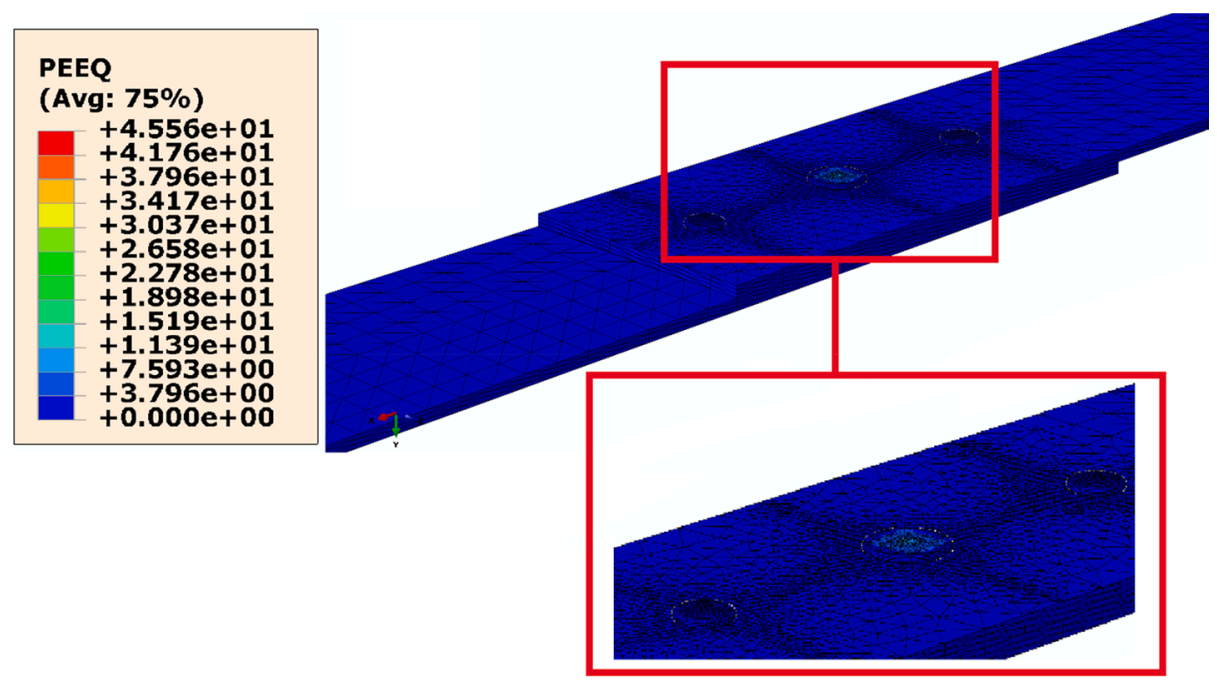

Fig. 3. PEEQ contour for level 1 parameters. 


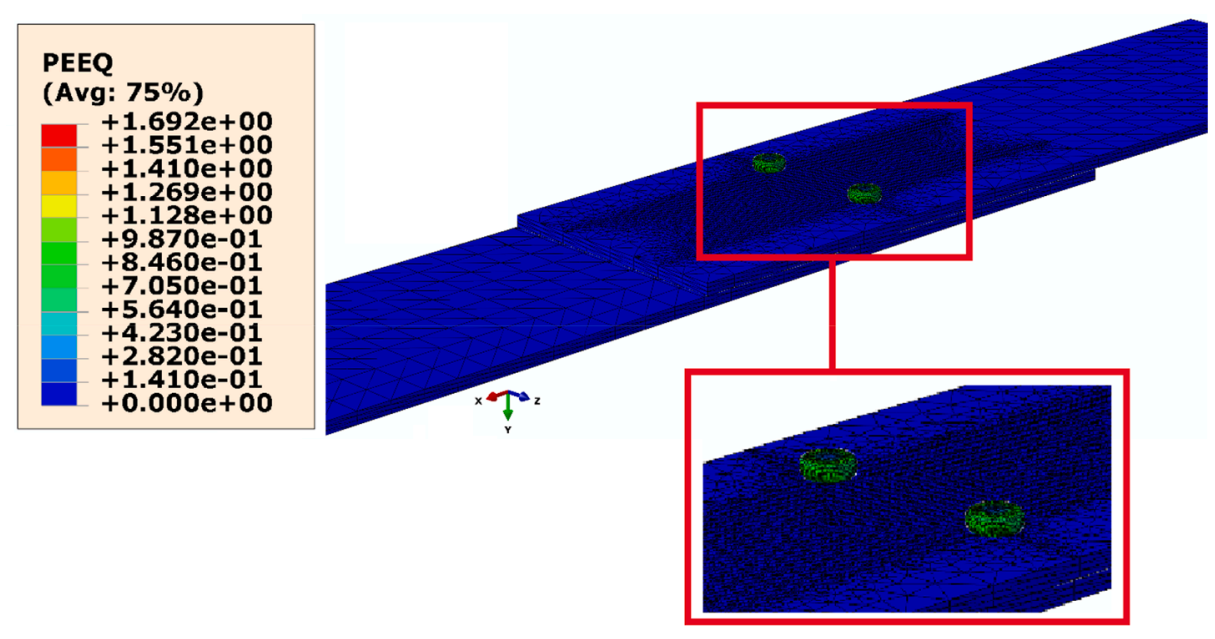

Fig. 4. PEEQ contour for level 2 parameters.

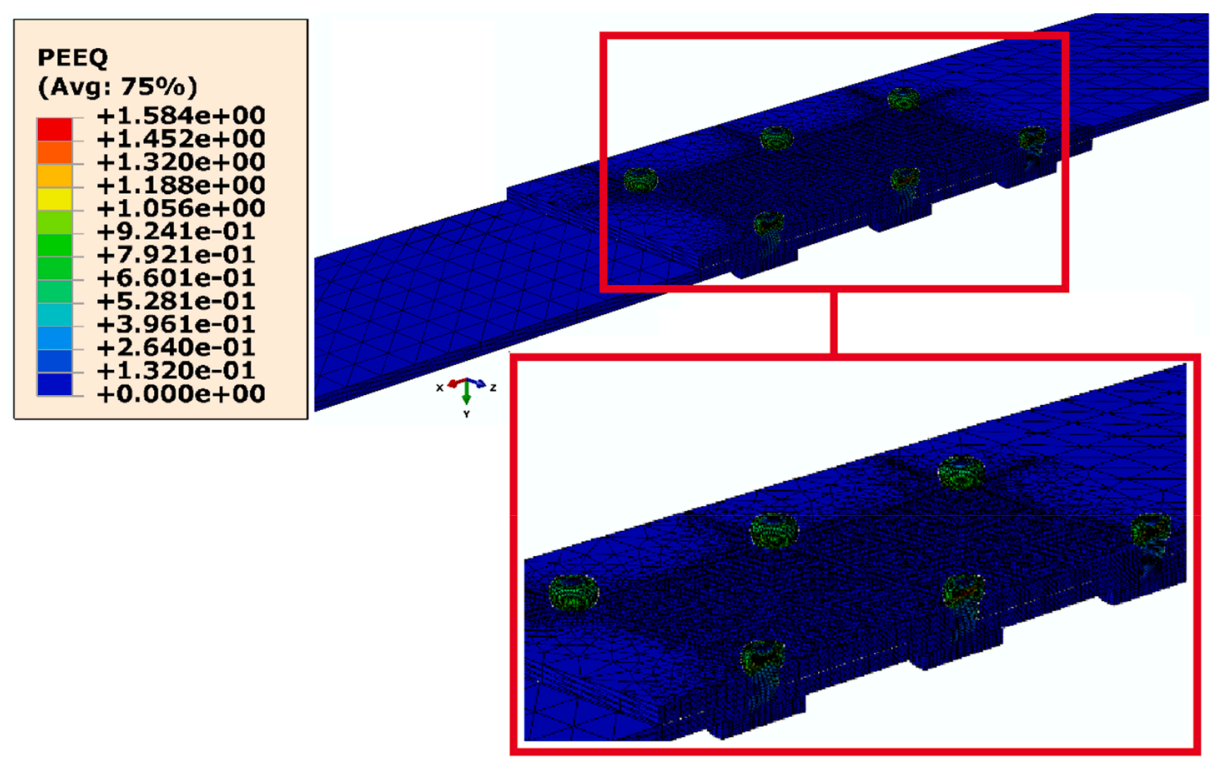

Fig. 5. PEEQ contour for level 3 parameters.

Table 4

Maximum PEEQ results.

\begin{tabular}{llll}
\hline parameters & Level 1 & Level 2 & Level 3 \\
\hline Max PEEQ & 2.989 & 0.417 & 0.305 \\
\hline
\end{tabular}

where $C$ and $m$ are material constants that equal to $C=9.97 \times$ $10^{-9} \mathrm{~m} /$ cycle, $m=3.97$ respectively [46].

FRANC3D software written by Cornell University researchers has been used to simulate fatigue crack growth [47-49]. Fig. 10 shows the boundary element model and the crack in it, which has used more elements to achieve better results around the crack and the place of contact load. In this study, the geometry of the crack emanating from the sheet's hole is semi-elliptical shape. According to field observations, the first row in adjacent to the edge of the front sheets, which is actually the last row of rivets at the back sheet, is failed. The crack length studied in this study is 1,2 and $3 \mathrm{~mm}$, which is considered as the initial crack.

After loading, the specimen is meshed and numerical analysis is performed through boundary element solver (BES). Then the values of the stress intensity factors are calculated. After calculating the values of stress intensity factor, the direction of fatigue crack growth is also determined. Once the fatigue crack growth direction is determined, the crack tip curve can be fitted and the fatigue crack can be grown for one step. After the fatigue crack grows, the specimen is meshed again and prepared for dissolution and this must be repeated for each stage of fatigue crack growth. Then, after entering the necessary data and after calculating the values of stress intensity factor, the fatigue life for the Alalloy 2024 plate in riveted joint is calculated using Eq. (3).

Fatigue life prediction for levels 1, 2 and 3 are presented in Table 5. As the initial crack length increases, the fatigue life decreases. As can be seen, level 1 and an initial crack length of $3 \mathrm{~mm}$ have the shortest fatigue life. Comparison of the results showed that the initial crack length for all three levels has a significant effect on the fatigue life of the riveted joint. According to these results, the final fatigue life for the initial crack with a crack length of $1 \mathrm{~mm}$ and for level 3 is longer than other levels.

As can be seen in Table 5 , the fatigue life has increased by about $13 \%$ by changing the geometry parameters for the initial crack length of 1 $\mathrm{mm}$ from level 1 to level 2 by about 13\% and from level 1 to level 3 by about $25 \%$. The fatigue life of 2024 aluminum plates has been increased by about $16 \%$ and from level 1 to level 3 by about $27 \%$ by changing the geometry parameters for the initial crack length of $2 \mathrm{~mm}$ from level 1 to level 2. Also, the fatigue life of 2024 aluminum plates has been increased by about $19 \%$ by changing the geometry parameters for the initial crack 


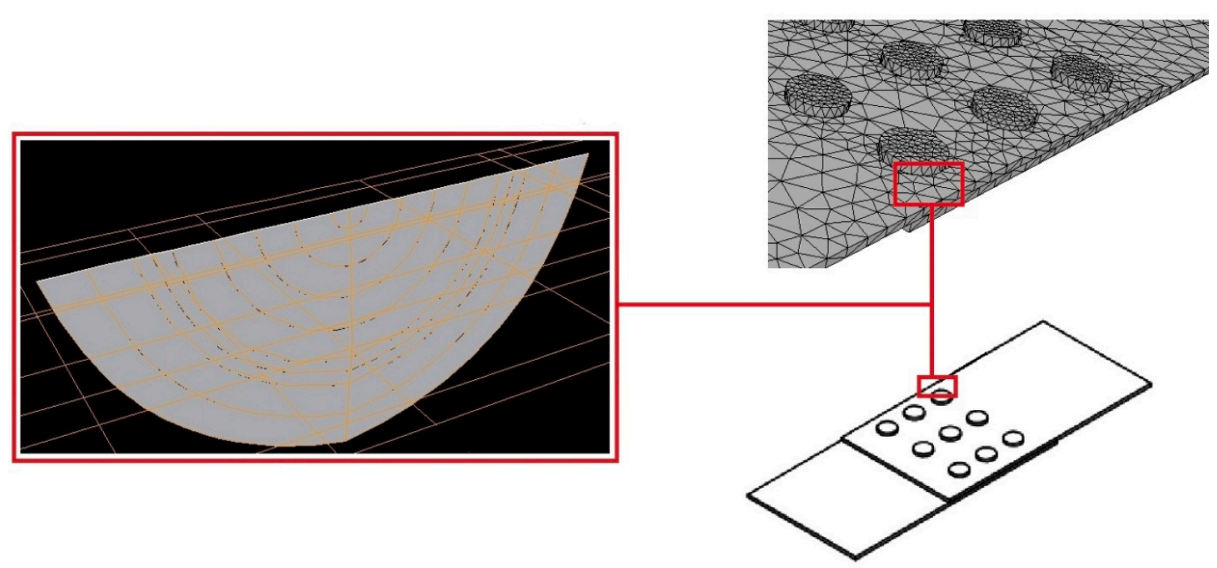

Fig. 6. Boundary element model of the studied sample.

Table 5

Fatigue crack growth simulation results for three level parameters.

\begin{tabular}{llll}
\hline $\begin{array}{l}\text { Initial crack } \\
\text { length } \\
(\mathrm{mm})\end{array}$ & $\begin{array}{l}\text { Specimen life for } \\
\text { level 1 parameter } \\
\text { (cycles) }\end{array}$ & $\begin{array}{l}\text { Specimen life for } \\
\text { level 2 parameter } \\
\text { (cycles) }\end{array}$ & $\begin{array}{l}\text { Specimen life for } \\
\text { level 3 parameter } \\
\text { (cycles) }\end{array}$ \\
\hline 1 & 4832 & 5611 & 6426 \\
2 & 4601 & 5459 & 6289 \\
3 & 4056 & 5009 & 5871 \\
\hline
\end{tabular}

length of $3 \mathrm{~mm}$ from level 1 to level 2 by about $19 \%$ and from level 1 to level 3 by about $31 \%$.

\section{Conclusions}

Many parameters affect the performance of riveted joints over time due to different loads. Parameters such as the material of riveted joints, the geometry and the dimensional tolerance of riveted joints can be mentioned. Given the breadth of these factors, study is essential to achieve a proper joint in terms of longevity and safety. In this study, finite element tests have been designed and finally the best riveted joint with the longest fatigue life has been found. The parameters studied were the rivet shank length, the rivet shank diameter, the punch pressure, the number of lateral holes and the number of longitudinal holes. Finite element simulation has been investigated to find the maximum equivalent plastic strain (MAX PEEQ) for 3 levels of different parameters. Then, the fatigue life of these three levels was evaluated using the boundary element method. The lowest equivalent plastic strain was in the case where the rivet shank diameter was $2.8 \mathrm{~mm}$, the pressure was $1.8 \mathrm{Sy}$ and the rivet shank length was $9 \mathrm{~mm}$, and as a result, the levels determined in this level were considered the best for this riveted joint. A slight increase in crack length reduces fatigue life. Therefore, the stress intensity factor for small cracks is much more important than the stress intensity factor for large cracks. The results showed that the fatigue life of level 3 with an initial crack of $1 \mathrm{~mm}$ has the longest fatigue life compared to other levels. Also, the lowest fatigue life is related to the parameters considered in level 1 with an initial crack length of $3 \mathrm{~mm}$. For future research, some parameters affecting fatigue life such as the friction coefficient between rivet and plate, rivet shank diameter change, and structural defects of the plate are in line with this paper.

\section{Declaration of Competing Interest}

The authors declare that they have no known competing financial interests or personal relationships that could have appeared to influence the work reported in this paper.

\section{Acknowledgement}

Reza Masoudi Nejad is supported by the International Postdoctoral Exchange Fellowship Program (Talent-Introduction Program) of the P. R. China (Fund No. 234384).

\section{References}

[1] Masoudi Nejad R, Tohidi M, Darbandi AJ, Saber A, Shariati M. Experimental and numerical investigation of fatigue crack growth behavior and optimizing fatigue life of riveted joints in Al-alloy 2024 plates. Theor Appl Fract Mech 2020;108: 102669.

[2] Saber A, Shariati M, Nejad RM. Experimental and numerical investigation of effect of size, position and geometry of some cutouts on fatigue life and crack growth path on AISI1045 steel plate. Theor Appl Fract Mech 2020;107:102506.

[3] Mortazavian E, Wang Z, Teng H. Repair of light rail track through restoration of the worn part of the railhead using submerged arc welding process. Int J Adv Manufact Technol 2020;107(7):3315-32.

[4] Krause, A.R., Cherenkoff, R.A., "A comparative study of fatigue behavior of spotwelded and mechanically fastened aluminum joints", Society of Automotive Engineers, SAE paper number: 3960710, 1995.

[5] Ferro P, Petrone N. Asymptotic thermal and residual stress distributions due to transient thermal loads. Fatigue Fract Eng Mater Struct 2009;32(11):936-48.

[6] Ferro P. Influence of phase transformations on the asymptotic residual stress distribution arising near a sharp V-notch tip. Modell Simul Mater Sci Eng 2012;20 (8):085003.

[7] Borsato T, Ferro P, Berto F, Carollo C. Mechanical and fatigue properties of heavy section solution strengthened ferritic ductile iron castings. Adv Eng Mater 2016;18 (12):2070-5.

[8] Hahn, O., Meschut, G., Peetz, A., "Mechanical properties of punch-riveted and adhesive bonded aluminum sheets", Weld Cutt, Vol. 51(7), 1999.

[9] Fu, M., Mallick, P.K., "Effect of process variables on the static and fatigue properties of self-piercing riveted joints in aluminum alloy 5754", Society of Automotive Engineers, SAE paper number 2001-01-0825, 2001.

[10] Fu M, Mallick PK. Fatigue of self-piercing riveted joints in a aluminum alloy 6111. Int J Fatigue 2003;25:183-9.

[11] Iyer K, Hu SJ, Brittman FL, Wang PC, Hayden DB, Marin SP. Fatigue of single-and double- rivet self-piercing riveted lap joints. Fatigue Fract Engng Mater Struct 2005;28:997-1007.

[12] Ekvall JCE. Fatigue of riveted metallic joints. ASTM STP 1986;927:172-89.

[13] Fung CP, Smart J. An experimental and numerical analysis of riveted single lap joints. Proc Inst Mech Eng 1996;208:79-90.

[14] Szolwinski MP, Farris TN. Linking riveting process parameters to the fatigue performance of riveted aircraft structures. J Aircraft 2000;37(1):130-7.

[15] Shariati M, Mohammadi E, Masoudi Nejad R. Effect of a new specimen size on fatigue crack growth behavior in thick-walled pressure vessels. Int J Press Vessels Pip 2017;150:1-10.

[16] Masoudi Nejad R, Farhangdoost Kh, Shariati M. Three-dimensional simulation of rolling contact fatigue crack growth in UIC60 rails. Tribol Trans 2016:1059-69.

[17] Masoudi Nejad R, Farhangdoost Kh, Shariati M, Moavenian M. Stress intensity factors evaluation for rolling contact fatigue cracks in rails. Tribol Trans 2016;60 (4):645-52.

[18] Masoudi Nejad R, Farhangdoost Kh, Shariati M. Microstructural analysis and fatigue fracture behavior of rail steel. Mech Adv Mater Struct 2020;27(2):152-64.

[19] Masoudi Nejad R. Three-dimensional analysis of rolling contact fatigue crack and life prediction in railway wheels and rails under residual stresses and wear. Ph. D. Thesis. School of Mechanical Engineering: Ferdowsi University of Mashhad; 2017.

[20] Masoudi Nejad R, Shariati M, Farhangdoost Kh. Prediction of fatigue crack propagation and fractography of rail steel. Theor Appl Fract Mech 2019;101: 320-31. 
[21] Masoudi Nejad R. Using three-dimensional finite element analysis for simulation of residual stresses in railway wheels. Eng Fail Anal 2014;45:449-55.

[22] Salehi SM, Farrahi GH, Sohrabpoor S, Masoudi NR. Life Estimation in the Railway Wheels under the Influence of Residual Stress Field. Int J Railway Res 2014;1(1): 53-60.

[23] Masoudi Nejad R, Farhangdoost Kh, Shariati M. Numerical study on fatigue crack growth in railway wheels under the influence of residual stresses. Eng Fail Anal 2015;52:75-89.

[24] Masoudi Nejad R, Shariati M, Farhangdoost Kh. Three-dimensional finite element simulation of residual stresses in UIC60 rails during the quenching process. Therm Sci 2017;21(3):1301-7.

[25] Hadipour M, Alambeigi F, Hosseini R, Masoudinejad R. A study on the vibrational effects of adding an auxiliary chassis to a 6-ton truck. J Am Sci 2011;7(6):1219-26.

[26] Ghahremani Moghadam D, Farhangdoost Kh, Masoudi Nejad R. Microstructure and Residual Stress Distributions Under the Influence of Welding Speed in Friction Stir Welded 2024 Aluminum Alloy. Metallurg Mater Trans B 2016;47(3):2048-62.

[27] Masoudi Nejad R, Shariati M, Farhangdoost Kh, Atrian A. Rolling contact fatigue analysis of rails under the influence of residual stresses induced by manufacturing. Scientia Iranica 2018;26(3):1427-37.

[28] Shariati M, Masoudi Nejad R. Fatigue Strength and Fatigue Fracture Mechanism for Spot Welds in U-Shape Specimens. Latin Am J Solids Struct 2016;13(15): 2487-501.

[29] Masoudi Nejad, Reza "Rolling contact fatigue analysis under influence of residual stresses.” MS Thesis, Sharif University of Technology, School of Mechanical Engineering; 2013.

[30] Nejad M, Reza SMS, Farrahi GH. Simulation of railroad crack growth life under the influence of combination mechanical contact and thermal loads. in 3rd International Conference on Recent Advances in Railway Engineering. 2013.

[31] Nejad M, Reza SM, Salehi GHF, Chamani M. Simulation of crack propagation of fatigue in Iran rail road wheels and Effect of residual stresses. In: Proceedings of the 21st International Conference on Mechanical Engineering. 2013.

[32] Shariati M, Mirzaei M, Masoudi Nejad R. An applied method for fatigue life assessment of engineering components using rigid-insert crack closure model. Eng Fract Mech 2018;204:421-33.

[33] Trego A, Cope D. Evaluation of damage tolerance analysis tools for lap joints. AIAA J 2001;39(12):2250-4.

[34] Blanchot V, Daidie A. Riveted assembly modeling: study and numerical charecterisation of a riveting process. J Mater Process Technol 2006;180:201-9.

[35] De Rijck JJM, Homan JJ, Schijve J, Benedictus R. The driven rivet head dimensions as an indication of the fatigue performance of aircraft lap joints. Int J Fatigue 2007; 29:2208-18.
[36] Kaifu Z, Hui C, Yuan L. Riveting process modeling and simulating for deformation analysis for aircraft's thin-walled sheet metal parts. Chin J Aeronaut 2011;24: 369-77.

[37] Beuth JL, Hutchinson JW. Fracture analysis of multi-site cracking in fuselage lap joints. Comput Mech 1994;13:315-31.

[38] Wang HL, Grandt AL. "Fatigue analysis of multiple site damage in lap joint specimens", Fatigue and Fracture Mechanics, ASTM STP 1360. Am Soc Test Mater 2000;30:214-26.

[39] Park CU, Grandt AF, Suh JJ. Stress intensity factors for surface cracks at countersunk holes. Eng Fract Mech 2006;73:1878-98.

[40] Moreira PMGP, Matos PFP, Camanho PP, Pastrama SD, Castro PMST. Stress intensity factor and load transfer analysis of a cracked riveted lap joint. Mater Des 2007;28:1263-70.

[41] Zamani P, Mojarzadeh S, Masoudinejad R, Farhangdoost Kh. Numerical investigation on optimizing fatigue life in a lap joint structure. World Academy of Science. Eng Technol 2015;9(5):609-15.

[42] Ghasemi H, Masoudi Nejad R, Darbandi AJ, Beni YT, Shariati M. Fatigue and fracture behavior of A516 steel used in thick-walled pressure vessels. Scientia Iranica 2020;27(6):2904-12.

[43] Masoudi Nejad R, Shariati M, Farhangdoost Kh. Effect of wear on rolling contact fatigue crack growth in rails. Tribol Int 2016;94:118-25.

[44] Aliakbari K, Imanparast M, Nejad RM. Microstructure and fatigue fracture mechanism for a heavy-duty truck diesel engine crankshaft. Scientia Iranica 2019; 26(6):3313-24.

[45] Masoudi Nejad R, Liu Z. Analysis of fatigue crack growth under mixed-mode loading conditions for a pearlitic Grade 900A steel used in railway applications. Eng Fract Mech 2021;107672.

[46] Ghahremani MD. Determination of stress intensity factors by extracting the shearography frings in welded CT specimens under cyclic load. Ph. D. Thesis. School of Mechanical Engineering: Ferdowsi University of Mashhad; 2016.

[47] Masoudi Nejad R. The effects of periodic overloads on fatigue crack growth in a pearlitic Grade 900A steel used in railway applications. Eng Fail Anal 2020;115: 104687.

[48] Masoudi Nejad R. Numerical study on rolling contact fatigue in rail steel under the influence of periodic overload. Eng Fail Anal 2020;115:104624.

[49] Masoudi Nejad R, Liu Z. Effect of periodic overloads and spectrum loading on fatigue life and microstructure in a Grade 900A rail steel. Theor Appl Fract Mech 2020;110:102796. 